\title{
Brand Franchise Supply Chain Partnership Based on Online and Offline Integrating Strategy
}

\author{
Rong Wang \\ Antai College of Economics \& Management, Shanghai Jiao Tong University, Shanghai, China. \\ Email: rwang@sjtu.edu.cn
}

Received June $23^{\text {rd }}, 2013$; revised July $20^{\text {th }}, 2013$; accepted July $27^{\text {th }}, 2013$

Copyright (C) 2013 Rong Wang. This is an open access article distributed under the Creative Commons Attribution License, which permits unrestricted use, distribution, and reproduction in any medium, provided the original work is properly cited.

\begin{abstract}
Taking advantage of online shopping affecting major parameters of corporate business including customer experience, customer word-of-mouth diffusion and customer complaints sharing, price elastic of consumer demand, and consumer brand loyalty, this paper focuses on the role of brand franchise supply chain partnership in the online and offline integrating environment. The findings suggest that the transfer payment shall be the critical contract clause to coordinate the brand franchise supply chain partnership to implement Pareto optimal strategy on VMI policy. Moreover, the optimal transfer payment has a strong positive relativity with the complementary of the online-offline shopping and VMI scale economic effect, whereas negative relativity with the substitutability of the online-offline shopping and VMI holding cost. The more VMI scale economic effect enhances, the larger online-offline integrating shopping market shares and the more system revenue shall be obtained in the brand franchise supply chain whereas taking advantage of the less transfer payment. The more VMI holding cost decreases, the larger online-offline integrating shopping market shares and the more system revenue shall be obtained in the brand franchise supply chain whereas taking advantage of the less transfer payment.
\end{abstract}

Keywords: Brand Franchise Supply Chain; Transfer Payment Contract; Online-Offline Integrating Strategy; VMI Policy; Scale Economic Effect

\section{Introduction}

Since the Internet-based e-commerce (electronic commerce or Internet commerce) emerging with the creation of Amazon.com and Yahoo.com in 1995, the incredibly rapid evolution of the Internet from 1995 till the present time makes the worldwide internet users hit 2.749 billion from 16 million of 1995 and the global Internet penetration rate rises to $38.8 \%$ from $0.4 \%$ of 1995 while the Internet penetration rate in the developed countries such as the United States, Japan, South Korea and Germany has reached over $78 \%, 79.5 \%, 82.5 \%$ and $83 \%$ for June 30 of 2012, respectively [1].

Alba et al. (1997) and some relevant literatures have been conducted exploring the consumer behaviors online which are different from traditional offline shopping environment, and the differences ultimately impact brand image, customer loyalty, corporate profitability and the overall corporate value in turn [2-5].

According to the annual statistical reports released by China Internet Network Information Center, the present
Internet penetration rate of $42.1 \%$ from $8.5 \%$ of 2005 in China has surpassed the global average level $38.8 \%$, with along the utilization ratio of online shopping rising over $42.9 \%$ from $22.1 \%$ of 2007 in China [6]. The emergence and growth of a series of e-commerce services in China promote significantly the rapid growth of the consumption scale and have a huge impact on the future of China's economy. By the end of December 2012, China has had a total of 564 million Internet users and more than 242 million online shoppers as exhibited in Table 1.

The customers no matter whether they are online or offline are unshackled and empowered to find, rate, review and comment products and services easily facilitated by social network websites, e-mails, discussion groups, blogs, tweets, mobile applications and so forth. The annual customer surveys reveal that today's customers regardless of online or offline shopping are increaseingly sophisticated and less tolerant of poor customer experience, with 89 percent of consumers saying they will never go back to an organization after a bad customer experience, up from 68 percent in 2006. And 86 
Table 1. Growth of internet users and online shopping users in China from 2007 to 2012.

\begin{tabular}{ccccc}
\hline Year & $\begin{array}{c}\text { Internet } \\
\text { Users } \\
\text { (Million) }\end{array}$ & $\begin{array}{c}\text { Internet } \\
\text { Penetration } \\
\text { Rate }\end{array}$ & $\begin{array}{c}\text { Online Shopping } \\
\text { Users } \\
\text { (Million) }\end{array}$ & $\begin{array}{c}\text { Utilization Ratio } \\
\text { of Online } \\
\text { Shopping }\end{array}$ \\
\hline 2005 & 111.00 & $8.5 \%$ & - & - \\
2006 & 137.00 & $10.5 \%$ & - & - \\
2007 & 210.00 & $16.0 \%$ & 46.41 & $22.1 \%$ \\
2008 & 298.00 & $22.6 \%$ & 74.00 & $24.8 \%$ \\
2009 & 384.00 & $28.9 \%$ & 108.00 & $28.1 \%$ \\
2010 & 457.30 & $34.3 \%$ & 160.51 & $35.1 \%$ \\
2011 & 513.10 & $38.3 \%$ & 193.95 & $37.8 \%$ \\
2012 & 564.00 & $42.1 \%$ & 242.02 & $42.9 \%$ \\
\hline
\end{tabular}

Source: Adapted from The $17^{\text {th }}-31^{\text {st }}$ Statistical Report on Internet Development in China, CNNIC, January 2006-January 2013.

percent of consumers will pay more for a better customer experience while 79 percent of consumers who shared complaints about poor customer experience online had their complaints ignored [7].

Today's powerful brand is everything customers experiences about the product or service and the magical difference beyond their competing products and services. It can be seen that the new marketing era embedded in online and offline integrating strategy, long overdue, is heralded in. All online-offline business processes of the brand enterprise famous for this strategy such as sports retailer Nike and fast retailing UNIQLO, need to be integrated to deliver a consistent and holistic experience that stretches beyond the physical and rational experience.

Rothery (2008) thinks of 4Es instead of 4Ps from the traditional offline marketing mix strategy comprised of product, price, place and promotion. In the new marketing mix strategy of 4Es, where the product has evolved into the customer experience (integrating online and offline), the place ranges over everyplace (including online and offline), the price becomes exchange, and the promotion has turned into evangelism. Alternatively, the promotion is morphing with product as communications seek to engage customers with experiences [8]. This new online and offline integrating environment allows brand enterprises to listen to customers everyplace while all the time engaging customers, developing brand image and nurturing customer loyalty along with inherently enhancing brand power, ensuring preferred purchasing and encouraging repeat purchasing.

As to the brand enterprises, the powerful brand is the strategic intellectual asset which is embedded in the holistic experience online and offline that stretches beyond the physical and rational experience into the psychologycal and emotional experience about the brand product and service. The holistic experience including excellent product quality, on-time delivery and superior customer service, will be able to deliver and reflect the unconscious desires and aspirations from their customers. And then the truth is that their customers are simply exchanging some of their own aspirations and perceiving the magical difference beyond their competing products and services.

The focus of this paper is the role of supply chain partnerships in the online and offline integrating environment. The remainder of the paper is organized as follows. In the next section, we will firstly overview the relevant literatures on comparisons of consumer behaviors in online-offline environment and supply chain partnership coordinated with contracts. The third section will explore the basic models and assumptions of brand franchise supply chain partnership based-on the online-offline integrating strategy. Then, the fourth and fifth sections will analyze and present the key finds and managerial insights of the study on brand franchise supply chain coordination strategy on VMI Policy, followed by the concluding remarks in the last section.

\section{Relevant Literature}

\subsection{Comparisons of Consumer Behaviors in Online and Offline Environment}

Brynjolfsson and Smith (2000) find that the average prices for books and CDs were lower online in 1999, implying more price competition online than offline. However, they also find the price dispersion is lower in Internet channels than in conventional channels, reflecting the dominance of certain heavily branded retailers and branding, awareness, and trust remain important sources of heterogeneity among Internet retailers [9]. Shankar et al. (2001) study how the online medium affects the importance of price and the value of price search in the hospitality industry. Comparing online and offline shopper groups, they find that the online medium does not have a main effect on the importance of price, but it does increase the perceived value of price search and thus increases price sensitivity [10]. Degeratu et al. (2001) investigate how brand name, price, and other search attributes affect consumer choice behavior in online and conventional supermarkets. They find that the importance of brand name varies across category, price sensitivity is higher online because of the stronger signaling effect of online price cuts, and the combined effect of price and promotion is lower online than offline environment [11].

Danaher et al. (2003) compare online and offline consumer brand loyalty and find that high market share brands, and therefore are better-known brands, enjoy a loyalty advantage in the online store, with the reverse result for small market share brands. In all these studies, the online and offline customers come from two separate 
samples; therefore, observed differences in shopping behavior might not be caused by the shopping media, but might be inherent in these two groups of consumers [12]. Chu et al. (2008) observe households that shop interchangeably at the online and the offline stores in the same grocery chain and investigate their purchase behavior in specific product categories. Although nearly $90 \%$ of households in the sample shop both at online and offline stores, they find that, across 12 vastly different product categories, these households exhibit lower price sensitivities when they shop online than when they shop offline [13]. Granados et al. (2012) analyze the impact of the Internet on demand, by comparing the demand functions in the Internet and traditional air travel channels. The results suggest that consumer demand in the Internet channel is more price elastic for both transparent and opaque online travel agencies [14]. Li et al. (2013) develop a theoretical model to analyze the pricing strategies of competing retailers with asymmetric cross-selling capabilities when product demand changes and suggest that retailers with better opportunities for cross-selling have higher incentives to adopt loss-leader pricing on highdemand products than retailers with low cross-selling capabilities [15].

Taking advantage of online shopping affecting major parameters of corporate business including customer experience, customer word-of-mouth diffusion and customer complaints sharing, price elastic of consumer demand, and consumer brand loyalty, this paper focuses on the role of brand franchise supply chain partnership in the online and offline integrating environment.

\subsection{Supply Chain Partnership Coordinated with Contracts}

The supply chain parties are primarily concerned with optimizing their own profitable objectives, and that self serving focus often results in poor performance, however, Pareto optimal performance is achievable if the supply chain parties coordinate by contracts so that each party's objective becomes aligned with the supply chain's objective. In other words, no party has a profitable unilateral deviation from the supply chain contract because each party's profit is no worse off and at least one member is strictly better off with the coordinating contract. The supply chain contracting literatures have been widely researched and analyzed to coordinate the supply chain partnership [16,17].

Pasternack (1985), Donohue (2000), Taylor (2002) and Krishnan et al. (2004) have studied the return policies and buyback agreements for perishable commodities such as consumer electronics, computers, software, books, magazines, newspapers, cosmetics, and so forth, which the manufacturer offers retailers a partial credit for all unsold goods with the agreed-upon price clause can achieve the supply chain coordination [18-21].

Bassok and Anupindi (1997), Moinzadeh and Nahmias (2000), Cachon and Lariviere (2001) have analyzed the quantity commitment contract for a single product that specifies that the cumulative orders by a buyer, over a finite horizon, be at least as large as the given total minimum quantity commitment [22-24].

Eppen and Iyer (1997), Cachon and Swinney (2008) have researched on the backup agreements in fashion supply chain [25,26], Tsay (1999), Milner and Kouvelis (2005) have studied quantity flexibility contracts in electronics industry such as Sun Microsystems, IBM, contract manufacturers such as Solectron, and etc. [27,28]. Furthermore, Wang (2007) has analyzed systemically supply chain contract clauses on supplier flexibility and consequently put forward a supplier selection approach for downstream buyer based on supplier flexibility from the perspective of risk sharing in supply chain [29].

Barnes-Schuster (2002) have developed option contracts in the apparel industry, Cachon and Lariviere (2005) have demonstrated that revenue-sharing contracts to coordinate the supply chain partnership in the videocassette rental industry, and Wang (2006) have given the analysis of revenue sharing contracts with uncertain demand in supply chain [30-32].

Wang and Benaroch (2004) discuss supply chain coordination to analyze the decision of suppliers and buyers to do or not do business in electronic markets while selling perishable products with random demand and find that their decisions depend on the revenue structure of the power of electronic markets, and then Netessine and Rudi (2006) take the viewpoint of supply chain choice on the internet $[33,34]$. Wang (2010) extends the R\&D partnership contract coordination of information goods supply chain in government subsidy and finds that the perfect sharing contract may achieve greater effective coordination than non-linear transfer payment contract, along with the strengthening of the innovation basis and the extent to which partners absorb and transform technological innovation knowledge, and the improvement of intellectual property protection environment and the degree of intellectual property protection [35].

Chen (2013) examines the dynamic supply chain coordination for deteriorating goods under consignment and vendor-managed inventory contracts with revenue sharing from retailer-centric business-to-business transactions in both traditional markets and electronic markets, and shows that, in a cooperative setting, the electronic markets with a consigned revenue-sharing VMI contract tends to achieve lower retail prices, larger stock quantity, improved channel efficiency, and increases in both retailer and supplier profits through an additional one-part tariff. Additionally, consumers benefit from lower retail prices and society benefits from increased overall chan- 
nel profits in the cooperative channel and electronic markets [36].

On the basis of the fore research literatures, this paper proposes the brand franchise supply chain coordination model on VMI policy for modeling and analysis of the brand rand franchise supply chain partnership based on online-offline integrating strategy.

\section{Basic Models and Assumptions}

Consider a brand franchise supply chain consists of two members: one brand enterprise and one upstream VMI partner-supplier with vendor managed inventory i.e. VMI policy. Firstly, the notations and assumptions in the models developed will be stated in details as follows.

Based on the online-offline integrating strategy, brand franchise supply chain members listen to customers everyplace while all the time engaging customers, developing brand image and nurturing customer loyalty along with inherently enhancing brand power, ensuring preferred purchasing and encouraging repeat purchasing. And then we may suppose the brand enterprise expected market demand with the price-sensitive consumers in the online and offline integrating environment is

$$
\left\{\begin{array}{l}
p_{n}\left(d_{n}, d_{f}\right)=a-\left(d_{n}+\theta d_{f}\right) \\
p_{f}\left(d_{n}, d_{f}\right)=a-\left(d_{f}+\theta d_{n}\right)
\end{array}\right.
$$

where, $p_{n}$ and $p_{f}$ are the online shopping price and offline shopping price, $d_{n}$ and $d_{f}$ are the online shopping quantity and offline shopping quantity, respectively. The shopping differentiation parameter, denoted by $\theta(-1<\theta<1)$, represents the degree of substitutability of the online shopping and offline shopping as $\theta(0<\theta<1)$ is positive, and the online shopping and offline shopping are perfect substitutes for consumers if $\theta=1$; whereas, represents the degree of complementary of the online shopping and offline shopping as $\theta(-1<\theta<0)$ is negative, and the online shopping and offline shopping are perfect complements for consumers if $\theta=-1$.

For simplifying the analysis further, under the wholesale contract, the linear transfer payments the downstream brand enterprise purchasing the online shopping goods and offline shopping goods from the upstream VMI partner-supplier shall be expressed with the wholesale price $\mathrm{w}$ as

$$
T\left(d_{n}, d_{f}\right)=w \cdot\left(d_{n}+d_{f}\right)
$$

Similarly, as to the upstream VMI partner-supplier, for simplifying the analysis, the production costs with unit production $\operatorname{cost} c$, and especially annual inventory holding costs with scale economic effect $\alpha(0<\alpha \leq 1$, note that no scale economic effect if $\alpha=1$ ) for the onlineoffline shopping can be mathematically expressed as

$$
\begin{gathered}
C\left(d_{n}, d_{f}\right)=c \cdot\left(d_{n}+d_{f}\right) \\
H\left(d_{n}, d_{f}\right)=K\left(d_{n}+d_{f}\right)^{\alpha}, K>0 ; 0<\alpha \leq 1
\end{gathered}
$$

where, the annual-inventory-holding-cost parameter $K(K$ $>0)$ given in the above expression depends upon three main factors, including the annual cost-to-hold-inventory rate, the average product value, the relationship between the average inventory level and the annual demand throughput at the upstream VMI partner-supplier.

Accordingly, we define that the brand enterprise's and the upstream VMI partner-supplier's expected revenue function in the online-offline integrating environment is as shown by express (5) and (6), respectively:

$$
\begin{aligned}
\pi_{r}\left(d_{n}, d_{f}\right)= & p_{n}\left(d_{n}, d_{f}\right) \cdot d_{n}+p_{f}\left(d_{n}, d_{f}\right) \cdot d_{f} \\
-T\left(d_{n}, d_{f}\right)= & {\left[a-\left(d_{n}+\theta d_{f}\right)\right] \cdot d_{n} } \\
& +\left[a-\left(d_{f}+\theta d_{n}\right)\right] \cdot d_{f}-w \cdot\left(d_{n}, d_{f}\right) \\
\pi_{s}\left(d_{n}, d_{f}\right)= & T\left(d_{n}, d_{f}\right)-C\left(d_{n}, d_{f}\right)-H\left(d_{n}, d_{f}\right) \\
= & (w-c) \cdot\left(d_{n}+d_{f}\right)-K\left(d_{n}+d_{f}\right)^{\alpha}
\end{aligned}
$$

\section{Brand Franchise Supply Chain Coordination on VMI Policy without SEE}

Now, start with the case of brand franchise supply chain coordination on VMI policy without scale economic effect (SEE) that is the parameter $\alpha=1$, and we analyze the optimal strategy of the brand enterprise in choice of the linear transfer payment contract clause. So we have the following:

$$
\begin{aligned}
\underset{\theta, w}{\operatorname{Max}} \pi_{r}=\underset{\theta, w}{\operatorname{Max}}\{[ & \left.a-\left(d_{n}+\theta d_{f}\right)\right] \cdot d_{n} \\
& \left.+\left[a-\left(d_{f}+\theta d_{n}\right)\right] \cdot d_{f}-w \cdot\left(d_{n}+d_{f}\right)\right\}
\end{aligned}
$$

s.t. $-1<\theta<1, w>c$

From differentiation using the first order condition for $d_{n}$ and $d_{f}$, and then the optimal online shopping quantity and optimal offline shopping quantity may be obtained, respectively.

$$
\begin{gathered}
\left\{\begin{aligned}
\frac{\partial \pi_{r}}{\partial d_{n}} & =\left[a-\left(2 d_{n}+\theta d_{f}\right)\right]-\theta d_{f}-w=0 \\
\frac{\partial \pi_{r}}{\partial d_{f}} & =\left[a-\left(2 d_{f}+\theta d_{n}\right)\right]-\theta d_{n}-w=0
\end{aligned}\right. \\
d_{n}^{*}=d_{f}^{*}=\frac{a-w}{2(1+\theta)},-1<\theta<1, \alpha=1
\end{gathered}
$$

Next, we move the optimal strategy of the upstream VMI partner-supplier focusing the wholesale contract 
clause, substituting the optimal shopping quantities $d_{n}{ }^{*}$ and $d_{f}^{*}$, into Equation (6),

$$
\begin{aligned}
& \underset{\theta, w}{\operatorname{Max}} \pi_{s}=\operatorname{Max}\left[(w-c) \cdot \frac{a-w}{1+\theta}-K\left(\frac{a-w}{1+\theta}\right)^{\alpha}\right] \\
& \text { s.t. }-1<\theta<1, w>c, K>0, \alpha=1
\end{aligned}
$$

Then, from the first-order and second-order conditions, the optimal linear transfer payment can be determined as

$$
\begin{aligned}
& \left\{\begin{array}{l}
\frac{\partial \pi_{s}}{\partial w}=\frac{\partial\left[(w-c) \cdot \frac{a-w}{1+\theta}-K\left(\frac{a-w}{1+\theta}\right)\right]}{\partial w}=0 ; \\
\frac{\partial^{2} \pi_{s}}{\partial w^{2}}=-\frac{2}{1+\theta}<0
\end{array}\right. \\
& w^{*}=\frac{a+c+K}{2},-1<\theta<1, K>0, \alpha=1
\end{aligned}
$$

Correspondently, the optimal profiles of linear transfer payment contract coordination on VMI policy without scale economic effect in the online-offline integrating environment are solved as follows:

$$
\begin{gathered}
d_{n}^{*}=d_{f}^{*}=\frac{a-c-K}{4(1+\theta)},-1<\theta<1, K>0, \alpha=1 \\
\left\{\begin{array}{l}
\pi_{r}^{*}=\frac{(a-c-K)^{2}}{8(1+\theta)},-1<\theta<1, K>0, \alpha=1 \\
\pi_{s}^{*}=\frac{(a-c-K)^{2}}{4(1+\theta)},-1<\theta<1, K>0, \alpha=1
\end{array}\right.
\end{gathered}
$$

Now, observe the above Expressions (11) and (12) that the optimal online-offline integrating strategy including online-offline shopping optimal quantities (i.e. $d_{n}{ }^{*}$ and $\left.d_{f}^{*}\right)$, and the brand enterprise's and the upstream VMI partner-supplier's optimal expected revenues (i.e. $\pi_{r}{ }^{*}$ and $\left.\pi_{s}^{*}\right)$, are negative relevant with the degree of substituteability of the online shopping and offline shopping as $\theta$ $(0<\theta<1)$, whereas positive relevant with the degree of complementary of the online shopping and offline shopping as $\theta(-1<\theta<0)$, shown as Figure 1.

Thus, it is easy to see that

[Proposition 1] The upstream VMI partner-supplier has more incentive to implement Pareto optimal strategy in choice of the linear transfer payment contract clause for brand franchise supply chain coordination on VMI policy without scale economic effect.

\section{Brand Franchise Supply Chain Coordination on VMI Policy with SEE}

In this section, we focus on the analysis of brand franchise supply chain coordination on VMI policy with scale economic effect. In virtue of backwards induction,

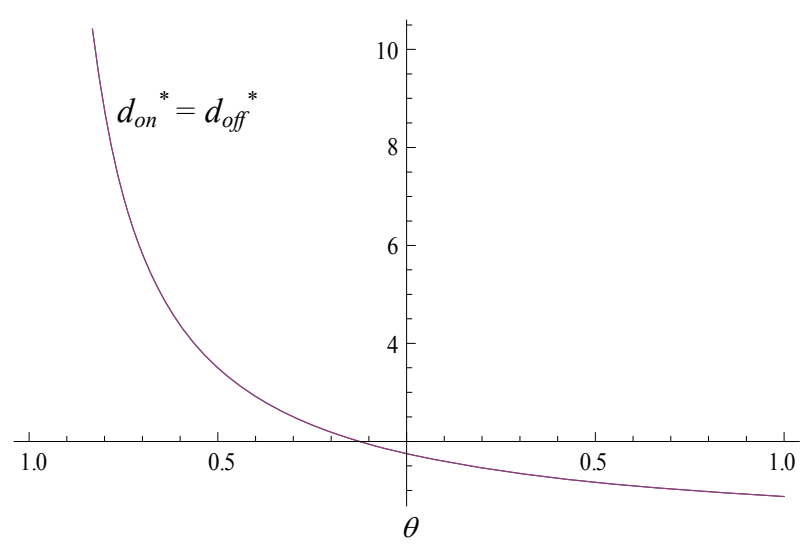

(a)

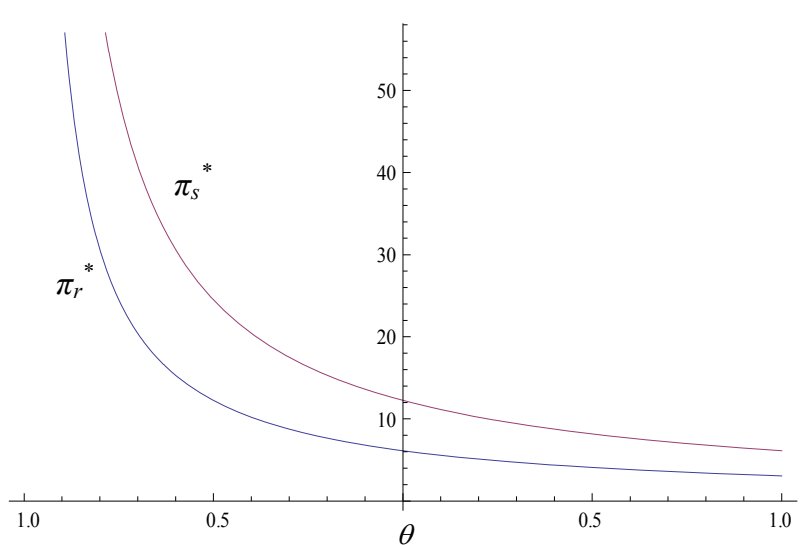

(b)

Figure 1. The numerical results in the optimal online-offline integrating strategy as $a=10, c=2, K=1, \alpha=1$. (a) Optimal online and offline integrating shopping quantities with $\theta$; (b) Brand franchise supply chain partners' expected revenue with $\theta$.

firstly, find the brand enterprise's optimal online-offline integrating strategy to maximize its own profit as a response to the wholesale contract clause, that is

$$
\begin{aligned}
& \underset{\theta, w}{\operatorname{Max}} \pi_{r}=\underset{\theta, w}{\operatorname{Max}}\left\{\left[a-\left(d_{n}+\theta d_{f}\right)\right] \cdot d_{n}\right. \\
& \left.+\left[a-\left(d_{f}+\theta d_{n}\right)\right] \cdot d_{f}-w \cdot\left(d_{n}+d_{f}\right)\right\} \\
& \text { s.t. }-1<\theta<1, w>c
\end{aligned}
$$

As a result, the optimal online shopping quantity and optimal offline shopping quantity generated is expressed as following

$$
d_{n}^{* *}=d_{f}^{* *}=\frac{a-w}{2(1+\theta)},-1<\theta<1, w>c
$$

Secondly, find the optimal strategy of the upstream VMI partner-supplier focusing the wholesale contract clause, substituting the optimal shopping quantities $d_{n}{ }^{*}$ and $d_{f}^{*}$, into Equation (6), 


$$
\begin{aligned}
& \underset{\theta, w}{\operatorname{Max}} \pi_{s}=\underset{\theta, w}{\operatorname{Max}}\left[(w-c) \cdot \frac{a-w}{1+\theta}-K\left(\frac{a-w}{1+\theta}\right)^{\alpha}\right] \\
& \text { s.t. }-1<\theta<1, w>c, K>0,0<\alpha<1
\end{aligned}
$$

Differentiating this expression with respect to $\pi_{s}$ and $w$ yields,

$$
\frac{\partial \pi_{s}}{\partial w}=\frac{\partial\left[(w-c) \cdot \frac{a-w}{1+\theta}-K\left(\frac{a-w}{1+\theta}\right)^{\alpha}\right]}{\partial w}=0
$$

Thus,

$$
\left\{\begin{array}{l}
G\left(w^{* *}\right)=a+c-2 w^{* *}+\alpha K\left(\frac{a-w^{* *}}{1+\theta}\right)^{\alpha-1}, \\
K>0,0<\alpha<1 ;-1<\theta<1
\end{array}\right.
$$

Ultimately, we have the following Stackelberg equilibrium policies in online-offline integrating environment are solved as following,

$$
\begin{gathered}
d_{n}^{* *}=d_{f}^{* *}=\frac{a-G\left(w^{* *}\right)}{2(1+\theta)}, K>0,0<\alpha<1 ;-1<\theta<1 \\
\left\{\begin{array}{l}
\pi_{r}^{* *}=\frac{\left[a-G\left(w^{* *}\right)\right]^{2}}{2(1+\theta)}, K>0,0<\alpha<1 ;-1<\theta<1 \\
\pi_{s}^{* *}=\left(G\left(w^{* *}\right)-c\right) \cdot \frac{a-G\left(w^{* *}\right)}{1+\theta}-K\left(\frac{a-G\left(w^{* *}\right)}{1+\theta}\right)^{\alpha}, \\
K>0,0<\alpha<1 ;-1<\theta<1
\end{array}\right.
\end{gathered}
$$

\subsection{Numerical Analysis on Substitutability and Complementary of the Online-Offline Shopping and Managerial Insights}

In the meantime, letting $a=10, c=2, K=1$ and $\alpha=0.5$ while $\theta$ is variable, for $-1<\theta<1$, the respective numerical simulation results of Equations (10) and (12) comparing to Equations (17) and (19) are illustrated in Figure 2.

As the Stackelberg leader, the upstream VMI partner-supplier shall make the effective contract clause "transfer payment $w$ " for the brand enterprise to promote the optimal online-offline integrating strategy. In this way, the brand franchise supply chain coordination on VMI policy with scale economic effect shall gain the more system revenue than VMI policy without scale economic effect whereas taking advantage of the less transfer payment $w$. Hence, we can further summarize,

[Proposition 2] The brand franchise supply chain partners have more incentive to implement Pareto optimal strategy in choice of the transfer payment contract clause for brand franchise supply chain coordination on VMI

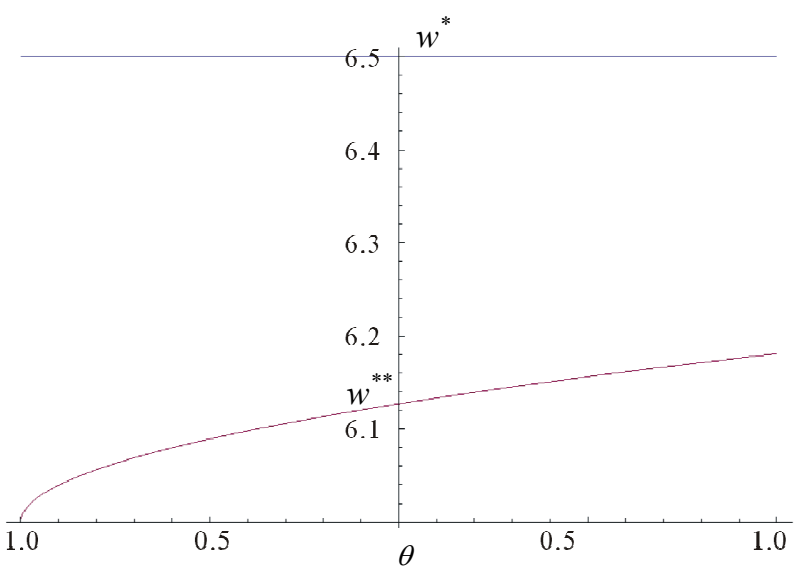

(a)

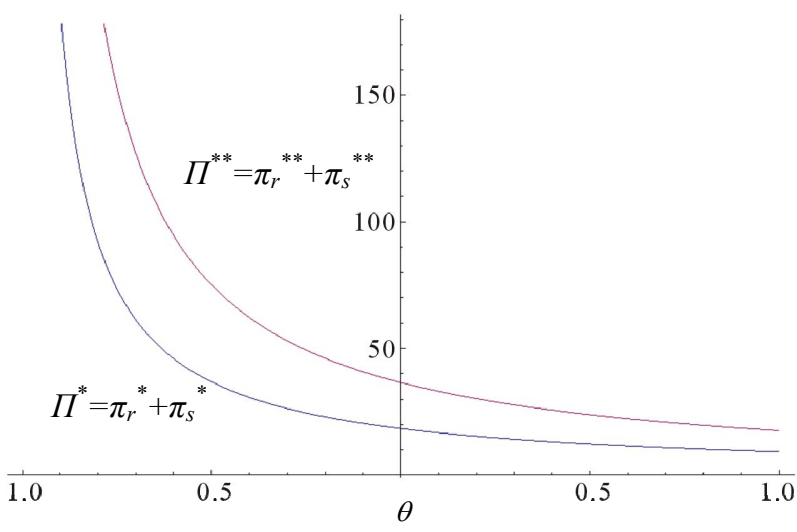

(b)

Figure 2. The numerical results in substitutability and complementary of the online-offline shopping as $a=10, c=2, K$ $=1, \alpha=0.5$. (a) Brand franchise supply chain contract clause with $\theta$; (b) Brand franchise supply chain system expected revenue with $\theta$.

policy with scale economic effect than the case of VMI policy without scale economic effect. Furthermore, the more incentive increases as the lower degree of substitutability of the online-offline shopping; whereas the more incentive increases as the higher the degree of complementary of the online-offline shopping.

\subsection{Numerical Analysis on VMI Scale Economic Effect and Managerial Insights}

Simultaneously, letting $a=10, c=2, K=1$ while $\alpha$ is given different levels and $\theta$ is variable, for $-1<\theta<1$, the respective numerical simulation results from the Equation (17) to the Equation (19) are illustrated in Figure 3. Therefore, the key managerial insight concluded from this analysis is as below.

[Proposition 3] As the VMI scale economic effect enhances $(0<\alpha \leq 1$, especially note that no scale economic effect if $\alpha=1$ ), the brand franchise supply chain partners have more incentive to implement Pareto optimal 


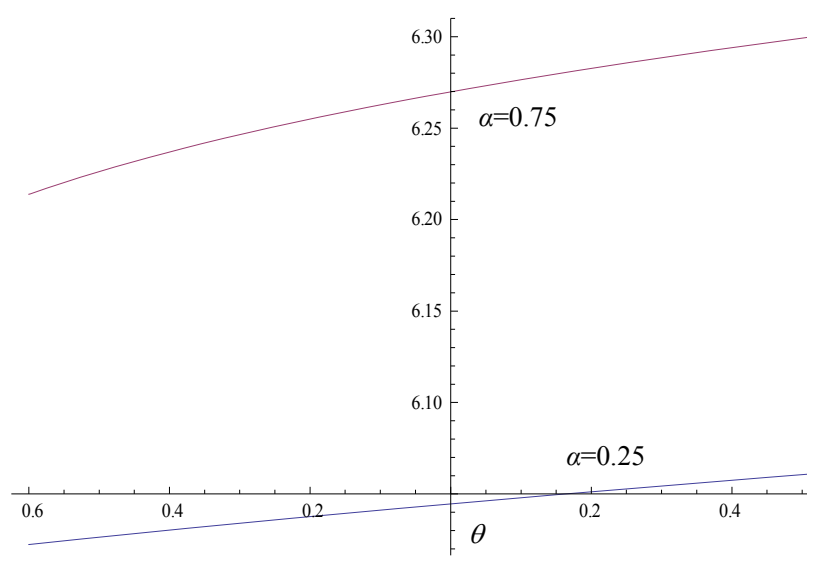

(a)

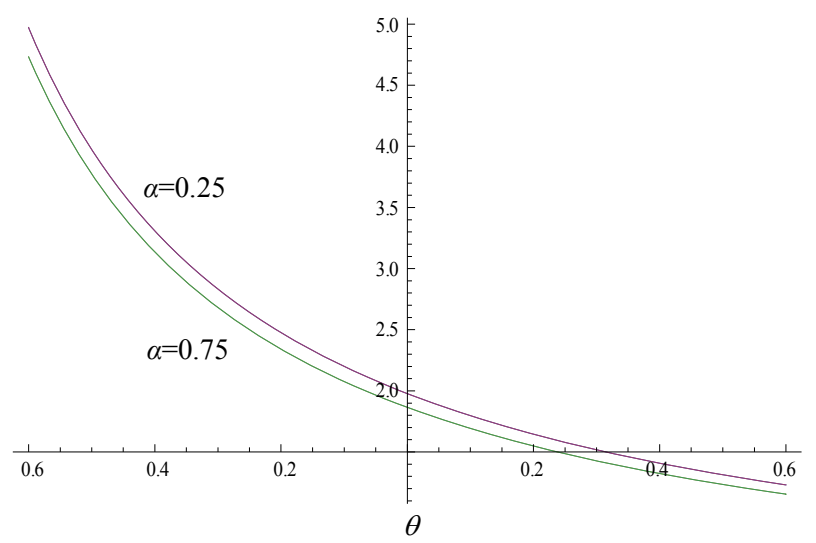

(b)

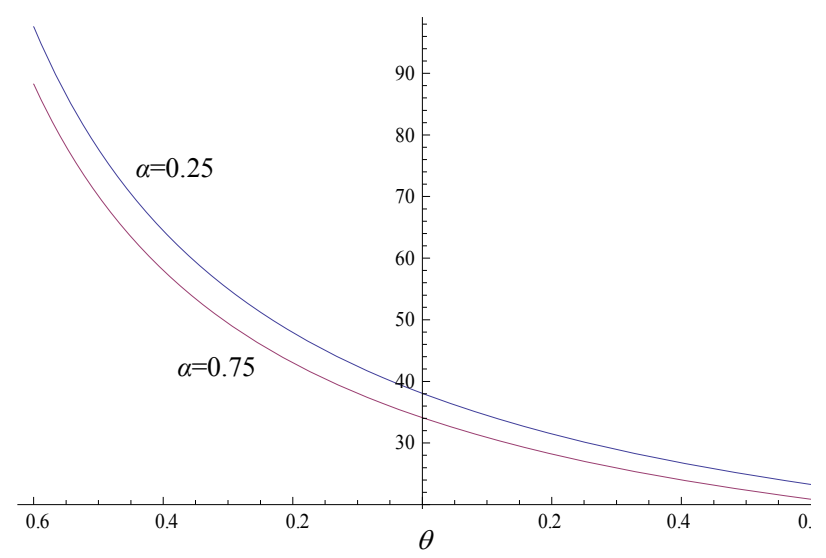

(c)

Figure 3. The numerical results in VMI scale economic effect as $a=10, c=2, K=1, \alpha=0.25$ vs. $\alpha=0.75$. (a) Brand franchise supply chain contract clause impacted by $\alpha$; (b) The optimal online-offline integrating shopping quantities impacted by $\alpha$; (c) Brand franchise supply chain system expected revenue impacted by $\alpha$.

strategy in choice of the wholesale contract clause "transfer payment $w$ " for brand franchise supply chain coordination on VMI policy. Furthermore, the more VMI scale economic effect enhances (that means the lower level of $\alpha$ ), the larger online-offline integrating shopping market share and the more system revenue shall be obtained in the brand franchise supply chain whereas taking advantage of the less transfer payment $w$.

\subsection{Numerical Analysis on VMI Holding Cost and Managerial Insights}

Finally, letting $a=10, c=2, \alpha=0.5$ while $K$ is given different levels and $\theta$ is variable, for $-1<\theta<1$, the respective numerical simulation results from the Expression (17) to Expression (19) are illustrated as Figure 4. In particular, the level of VMI holding cost parameter $K$ depends upon the annual cost-to-hold-inventory rate, the average product value, the relationship between the average inventory level and the annual demand throughput at the upstream VMI partner-supplier. As a result, the key managerial insight derived from this study can be seen in the following proposition.

[Proposition 4] As the VMI holding cost decreases, the brand franchise supply chain partners have more incentive to implement Pareto optimal strategy in choice of the wholesale contract clause "transfer payment $w$ " for brand franchise supply chain coordination on VMI policy. Furthermore, the more VMI holding cost decreases, the larger online-offline integrating shopping market share and the more system revenue shall be obtained in the brand franchise supply chain whereas taking advantage of the less transfer payment $w$.

\section{Concluding Remarks}

The purpose of this paper is to focus on the role of brand franchise supply chain partnership in the online and offline integrating environment. The key managerial insights derived from this study are that the "transfer payment w" shall be the critical contract clause to coordinate the brand franchise supply chain partnership to implement Pareto optimal strategy on VMI policy. Moreover, the "transfer payment $\mathrm{w}$ " has a strong positive relativity with the complementary of the online-offline shopping and VMI scale economic effect, whereas negative relativity with the substitutability of the online-offline shopping and VMI holding cost.

- The brand franchise supply chain partners have more incentive to implement Pareto optimal strategy in choice of the wholesale contract clause "transfer payment w" for brand franchise supply chain coordination on VMI policy, as the lower degree of substituteability of the online-offline shopping; whereas as the higher the degree of complementary of the onlineoffline shopping.

- The more VMI scale economic effect enhances, the larger online-offline integrating shopping market share and the more system revenue shall be obtained in the brand franchise supply chain whereas taking 


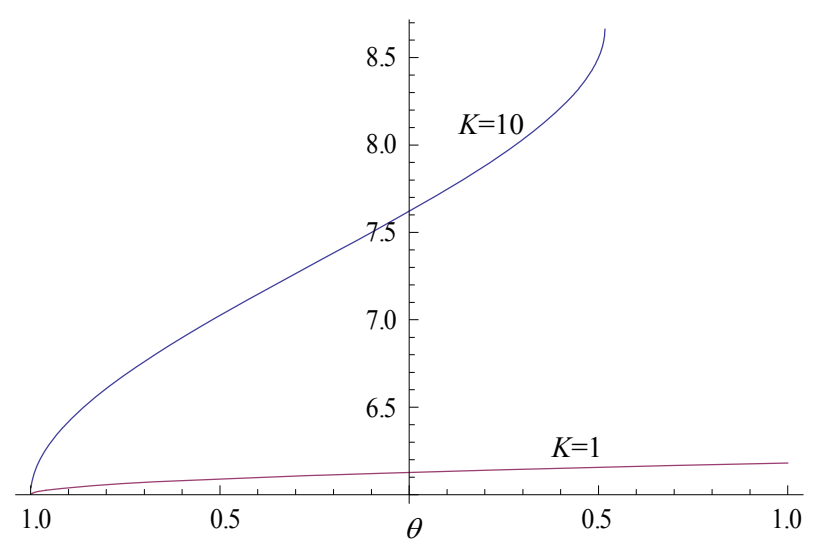

(a)

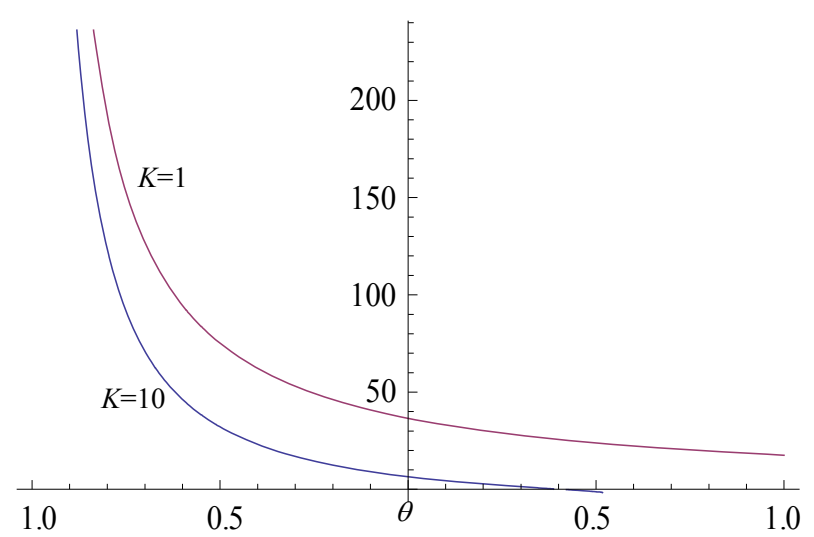

(b)

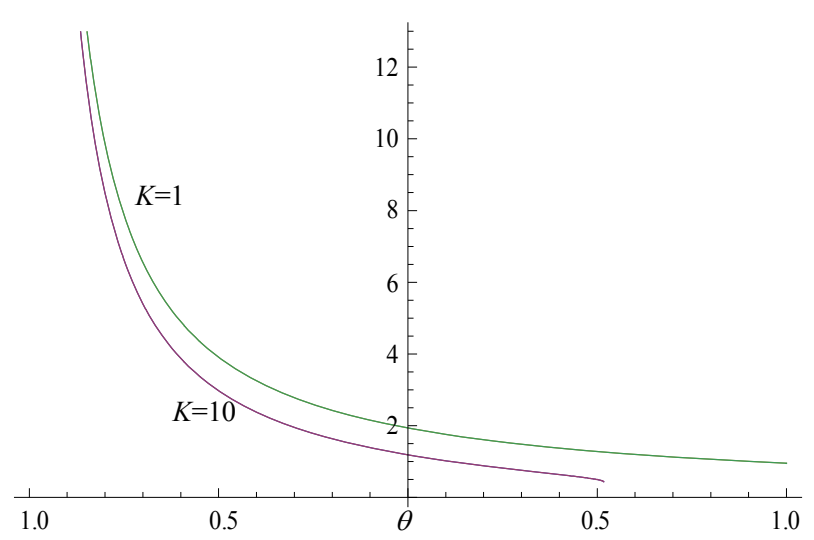

(c)

Figure 4. The numerical results in VMI holding cost as $a=$ $10, c=2, \alpha=0.5, K=1$ vs. $K=10$. (a) Brand franchise supply chain contract clause impacted by $K$; (b) The optimal online-offline integrating shopping quantities impacted by $K$; (c) Brand franchise supply chain system expected revenue impacted by $K$.

advantage of the less transfer payment.

- The more VMI holding cost decreases, the larger online-offline integrating shopping market share and the more system revenue shall be obtained in the brand franchise supply chain whereas taking advan- tage of the less transfer payment.

\section{REFERENCES}

[1] ITU, "History and Growth of the Internet from 1995 till Today," International Telecommunications Unions, Geneva, 2013.

[2] J. Alba, J. Lynch, B. Weitz, C. Janiszewski, R. Lutz, A. Sawyer and S. Wood, "Interactive Home Shopping: Consumer, Retailer, and Manufacturer Incentives to Participate in Electronic Marketplaces," Journal of Marketing, Vol. 61, No. 3, 1997, pp. 35-53. doi: $10.2307 / 1251788$

[3] E. Brynjolfsson and M. D. Smith, "Frictionless Commerce? A Comparison of Internet and Conventional Retailers," Management Science, Vol. 46, No. 4, 2000, pp. 563-585. doi:10.1287/mnsc.46.4.563.12061

[4] A. Chaudhuri and M. B. Holbrook, "The Chain of Effects from Brand Trust and Brand Affect to Brand Performance: The Role of Brand Loyalty", Journal of Marketing, Vol. 65 , No. 4, 2001, pp. 81-93. doi:10.1509/jmkg.65.2.81.18255

[5] A. M. Degeratu, A. Rangaswamy and J. Wu, "Consumer Choice Behavior in Online and Traditional Supermarkets: The effects of Brand Name, Price and Other Search Attributes," International Journal Research in Marketing, Vol. 17, No. 1, 2001, pp. 55-78. doi:10.1016/S0167-8116(00)00005-7

[6] CNNIC, "The 31st Statistical Report on Internet Development in China," China Internet Network Information Center, Beijing, 2013.

[7] M. L. Roberts and D. Zahay, "Internet Marketing," Wadsworth Publishing Company, Inc., Belmon, 2012.

[8] Harris Interactive, "The Annual Customer Experience Impact Report,” RightNow, 2012, pp. 1-6.

[9] C.-C. Chang and Y.-C. Chin, "Comparing Consumer Complaint Responses to Online and Offline Environment," Internet Research, Vol. 21, No. 2, 2011, pp. 124137. doi:10.1108/10662241111123720

[10] P. J. Danaher, I. W. Wilson and R. A. Davis, "A Comparison of Online and Offline Consumer Brand Loyalty," Marketing Science, Vol. 22, No. 4, 2003, pp. 461-476. doi:10.1287/mksc.22.4.461.24907

[11] P. K. Chintagunta, J. Chu and J. Cebollada, "Quantifying Transaction Costs in Online/Offline Grocery Channel Choice," Marketing Science, Vol. 31, No. 1, 2012, pp. 96-114. doi: $10.1287 / \mathrm{mksc} .1110 .0678$

[12] G. Rothery, “The Matchmaker," Marketing Age, 2008.

[13] J. Chu, P. Chintagunta and J. Cebollada, "A Comparison of Within-Household Price Sensitivity across Online and Offline Channels," Marketing Science, Vol. 27, No. 2, 2008, pp. 283-299. doi:10.1287/mksc. 1070.0288

[14] N. Granados, A. Gupta and R. J. Kauffman, "Online and Offline Demand and Price Elasticities: Evidence from the Air Travel Industry," Information Systems Research, Vol. 23, No. 1, 2012, pp. 164-181. doi: $10.1287 /$ isre. 1100.0312 
[15] X. Li, B. Gu and H. Liu, "Price Dispersion and LossLeader Pricing: Evidence from the Online Book Industry," Management Science, Vol. 59, No. 6, 2013, pp. 1290-1308. doi:10.1287/mnsc. 1120.1642

[16] Gérard P. Cachon, "Supply Chain Coordination with Contracts," In: S. Graves and T. de Kok, Eds., Handbooks in Operations Research and Management Science: Supply Chain Management, Chapter 6, North-Holland, Amsterdam, 2003.

[17] Y. Wang, "Overview of Supply Chain Contract Problem Driven by Customer Demand," Journal of Management Sciences in China, Vol. 8, No. 2, 2005, pp. 68-76.

[18] B. A. Pasternack, "Optimal Pricing and Return Policies for Perishable Commodities," Marketing Science, Vol. 4, No. 2, 1985, pp. 166-176. doi:10.1287/mksc.4.2.166

[19] K. L. Donohue, "Efficient Supply Contracts for Fashion Goods with Forecast Updating and Two Production Modes," Management Science, Vol. 46, No. 11, 2000, pp. 1397-1411. doi:10.1287/mnsc.46.11.1397.12088

[20] T. Taylor, "Supply Chain Coordination under Channel Rebates with Sales Effort Effects," Management Science, Vol. 48, No. 8, 2002, pp. 992-1007. doi: $10.1287 / \mathrm{mnsc} .48 .8 .992 .168$

[21] H. Krishnan and R. Kapuscinski and D. A. Butz, "Coordinating Contracts for Decentralized Supply Chains with Retailer Promotional Effort," Management Science, Vol. 50, No. 1, 2004, pp. 48-63. doi:10.1287/mnsc. 1030.0154

[22] Y. Bassok and R. Anupindi, "Analysis of Supply Contracts with Total Minimum Commitment," IIE Transactions, Vol. 29, No. 5, 1997, pp. 373-381. doi:10.1080/07408179708966342

[23] K. Moinzadeh and S. Nahmias, "Adjustment Strategies for a Fixed Delivery Contract," Operations Research, Vol. 48, No. 3, 2000, pp. 408-423.

[24] Gérard P. Cachon and Martin A. Lariviere, "Contracting to Assure Supply: How to Share Demand Forecasts in a Supply Chain" Management Science, Vol. 47, No. 5, 2001, pp. 629-646. doi:10.1287/mnsc.47.5.629.10486

[25] G. D. Eppen and A. V. Iyer, "Backup Agreements in Fashion Buying: The Value of Upstream Flexibility," Management Science, Vol. 43, No. 11, 1997, pp. 14691484.

[26] G. P. Cachon and R. Swinney, "The Impact of Strategic Consumer Behavior on the Value of Operational Flexibility," In: S. Netessine and C. Tang, Eds., Operations Man- agement Models with Consumer-Driven Demand, Chapter 14, Springer-Verlag, New York, 2009.

[27] A. A. Tsay, "The Quantity Flexibility Contract and Supplier-Customer Incentives," Vol. 45, No. 1, Management Science, 1999, pp. 1339-1358. doi: $10.1287 /$ mnsc. 45.10 .1339

[28] J. M. Milner and Panos Kouvelis, "Order Quantity and Timing Flexibility in Supply Chains: The Role of Demand Characteristics," Management Science, Vol. 51, No. 6, 2005, pp. 970-985. doi:10.1287/mnsc. 1050.0359

[29] R. Wang, "Analysis of Supply Chain Contract Clauses on Supplier Flexibility," Proceedings of 14th International Conference on Management Science \& Engineering, ICMSE'07, 20-22 August 2007, Harbin, pp. 627-632.

[30] D. Barnes-Schuster, Y. Bassok and R. Anupindi, "Coordination and Flexibility in Supply Contracts with Options," Manufacturing \& Service Operations Management, Vol. 4, No. 3, 2002, pp. 171-207. doi: $10.1287 / \mathrm{msom} .4 .3 .171 .7754$

[31] G. P. Cachon and M. A. Lariviere, "Supply Chain Coordination with Revenue-Sharing Contracts: Strengths and Limitations," Marketing Science, Vol. 51, No. 1, 2005, pp. 30-45.

[32] R. Wang, "Analysis of Revenue Sharing Contracts with Uncertain Demand in Supply Chain," Proceedings of 13th International Conference on Management Science \& Engineering, ICMSE'06, 5-7 October 2006, Lille, pp. 522-525.

[33] C. X. Wang and M. Benaroch, "Supply Chain Coordination in Buyer Centric B2B Electronic Markets," International Journal of Production Economics, Vol. 92, No. 4, 2004, pp. 113-124. doi:10.1016/j.ijpe.2003.09.016

[34] S. Netessine and N. Rudi, "Supply Chain Choice on the Internet," Management Science, Vol. 52, No. 6, 2006, pp. 844-864. doi: $10.1287 / \mathrm{mnsc} .1060 .0512$

[35] R. Wang, J. Ji and X. G. Ming, "R\&D Partnership Contract Coordination of Information Goods Supply Chain in Government Subsidy," International Journal of Computer Applications in Technology, Vol. 37, No. 3-4, 2010, pp. 297-306. doi:10.1504/IJCAT.2010.031945

[36] L. Chen, "Dynamic Supply Chain Coordination under Consignment and Vendor-Managed Inventory in RetailerCentric B2B Electronic Markets," Industrial Marketing Management, Vol. 42, No. 4, 2013, pp. 518-531. doi:10.1016/j.indmarman.2013.03.004 